\title{
Blockchain application and outlook in the banking industry
}

\author{
Ye Guo ${ }^{*}$ id and Chen Liang
}

\author{
* Correspondence: \\ eyguo@xmu.edu.cn \\ School of Economics, Xiamen \\ University, Xiamen 361005, China
}

\begin{abstract}
Blockchain technology is a core, underlying technology with promising application prospects in the banking industry. On one hand, the banking industry in China is facing the impact of interest rate liberalization and profit decline caused by the narrowing interest-rate spread. On the other hand, it is also affected by economic transformation, Internet development, and financial innovations. Hence, the banking industry requires urgent transformation and is seeking new growth avenues. As such, blockchains could revolutionize the underlying technology of the payment clearing and credit information systems in banks, thus upgrading and transforming them. Blockchain applications also promote the formation of "multi-center, weakly intermediated" scenarios, which will enhance the efficiency of the banking industry. However, despite the permissionless and self-governing nature of blockchains, the regulation and actual implementation of a decentralized system are problems that remain to be resolved. Therefore, we propose the urgent establishment of a "regulatory sandbox" and the development of industry standards.
\end{abstract}

Keywords: Blockchain, Decentralization, Banking industry transformation

\section{Review}

Blockchain is currently a concept that has received significant attention in financial technology (FinTech). It combines several computer technologies, including distributed data storage, point-to-point transmission, consensus mechanisms, and encryption algorithms. It has also been identified as a disruptive innovation of the Internet era. However, as blockchain is a major breakthrough in data storage and information transmission, it might fundamentally transform the existing operating models of finance and economy, which might lead to a new round of technological innovations and industrial transformation within the FinTech industry (Mu Qi-Guo 2016).

Recently, international institutions, including the United Nations and the International Monetary Fund, (The First Digital Currency Report of the International Monetary Fund $[\mathrm{EB} / \mathrm{OL}])$ as well as developed nations, such as the US, the UK, and Japan, have paid close attention to the development of blockchains and explored their application in various fields. Furthermore, China, Russia, India, South Africa, and other countries have also successively initiated research on blockchain technology. In February 2016, the governor of the People's Bank of China (PBOC), Zhou Xiaochuan, mentioned during a discussion on issues related to digital currencies that blockchain technology is a possible option. As such, PBOC has spent considerable resources researching the application

(c) The Author(s). 2016 Open Access This article is distributed under the terms of the Creative Commons Attribution 4.0 International License (http://creativecommons.org/licenses/by/4.0/), which permits unrestricted use, distribution, and reproduction in any medium, provided you give appropriate credit to the original author(s) and the source, provide a link to the Creative Commons license, and indicate if changes were made. 
of blockchain technology. On October 18, 2016, the Ministry of Industry and Information Technology published the "Chinese Blockchain Technology and Application Development White Paper (2016)," which analyzes the current status of blockchain technology and proposes recommendations for future development.

Blockchains are decentralized and permissionless, which can lead to major disruptions in the financial sector, especially in payment clearing. Since 2015, a number of major international financial institutions have begun to formulate plans for the blockchain sector. Goldman Sachs, J.P. Morgan, UBS, and other banking giants have all established their own blockchain laboratories, working in close collaboration with blockchain platforms, and published a series of studies on this topic. Goldman Sachs even filed a patent for transaction settlement based on blockchain technology. Additionally, various national stock exchanges, such as the Nasdaq Stock Market and the New York Stock Exchange have also conducted in-depth research on blockchain technology. On December 30, 2015, Nasdaq announced that it had completed its first securities transaction using the blockchain transaction platform Linq. Furthermore, the US Depository Trust \& Clearing Corporation, Visa, the Society for Worldwide Interbank Financial Telecommunication, etc. have also expanded their plans in the blockchain technology sector.

Different types of blockchain industrial consortiums have emerged in order to promote the development of blockchain technology and its applications, the R3 blockchain consortium being the most influential among them. It has brought together over 40 of the world's leading financial institution, including Bank of America, Citigroup, Morgan Stanley, Deutsche Bank, and Barclays Bank. As of May 2016, Ping An Bank and China Merchants Bank (CMB) have also joined the R3 blockchain consortium, thus strengthening the exchange and cooperation of top financial institutions in the blockchain technology. Additionally, WeBank, Ping An Bank, CMB Network Technology, among others, have formed the China Financial Blockchain Consortium. The major financial institutions have a relatively positive attitude toward improving the back-end processing efficiency of blockchain technology, and place significant emphasis on its potential to reduce operational costs.

There has also been widespread optimism regarding the application of blockchain in the banking industry. In May 2016, McKinsey conducted a survey on global banking executives, finding that approximately half of executives believe that blockchain will have a substantial impact within 3 years, with some even considering that this will happen within 18 months. ${ }^{1}$ Another survey of 200 global banks predicted that, by the following year, blockchain technology will be extensively implemented by $15 \%$ of banks. Furthermore, IBM has stated that, in 4 years, $66 \%$ of banks will have commercial blockchain at scale. ${ }^{2}$

As such, an increasing number of banks have begun to be pay greater attention and place emphasis on blockchains. Therefore, why is the current banking industry focusing on the deployment of blockchain strategies? Which specific scenarios can blockchains be applied to? What are the existing problems in the implementation process of blockchain technology? This paper discusses these questions in turn in the following sections.

\section{Blockchain technology is expected to transform the banking industry}

The banking industry in China is currently facing multiple pressures, including a decline in profits and an increase in risk, and has entered a new state of change and development. The sudden Internet finance boom has also led to numerous challenges in 
the traditional banking business. Consequently, commercial banks need to rely on new technological growth to accelerate product and service innovations, thereby adapting to new customer demands and competitive environments.

\section{Internal and external issues of the banking industry}

Impact of macroeconomic situation and policies

Since 2015, China's macroeconomy has entered a "new normal," wherein economic growth continues to decelerate, while interest rate liberalization is essentially complete, and their combined effects are becoming increasingly apparent. On one hand, there has been a trend towards narrowing interest-rate spread and declining the profitability of commercial banks. On the other hand, there has been increasing credit risk and nonperforming assets (Wang Wei 2016). The changes are shown in Figs. 1 and 2. Moreover, following a series of changes, including easing market access for foreign banks and the internationalization of the RMB, the survival environment of China's commercial banks has become particularly harsh.

\section{Internet finance boom with increased market share}

In recent years, booming Internet finance has accelerated the marketization of the financial sector. The endless emergence of Internet financial products has led to the substantial diversion of household saving deposits and increased banks' cost of debt. According to monitoring data for national Internet FinTech platforms, as of the end of August 2016, the number of Internet financial platforms had reached 8490 and the number of active users 618 million. The latest data released by the China Internet Network Information Center indicated that, as of June 2016, the number of Internet users in China was 710 million. As such, the percentage of Internet finance users accounts for $87 \%$ of total Internet users in China. ${ }^{3}$

The great success of Internet finance within a short period of time is due to four vantages: infrastructure, platforms, channels, and scenarios. Moreover, some details are shown in Table 1.

Internet finance companies are aware that finance is not an independent entity, but is embedded within numerous real-life scenarios. Therefore, the best method to expand the target market is to establish platforms on mobile terminals and provide application for various scenarios in order to occupy the customer's time. Presently, of the 20 brands of mobile phones most commonly used by Chinese consumers, 17 have either been acquired or invested into by Baidu, Alibaba, and Tencent. BAT ${ }^{4}$-owned applications account for nearly $40 \%$ of the total monthly duration of mobile phone usage, and this percentage can increase further to $60 \%$ if BAT-invested applications are also included. ${ }^{5}$

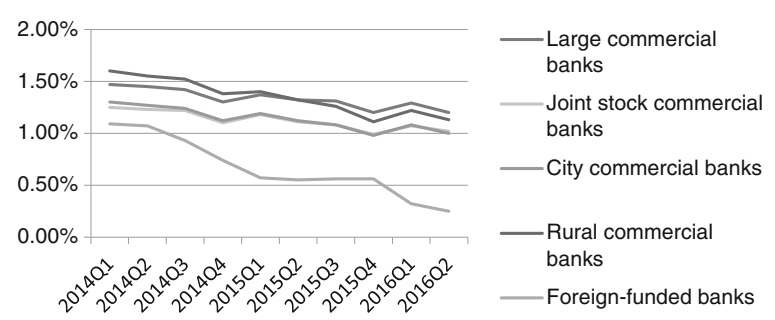

Fig. 1 Return on Assets for Commercial Banks. Source: China Banking Regulatory Commission 


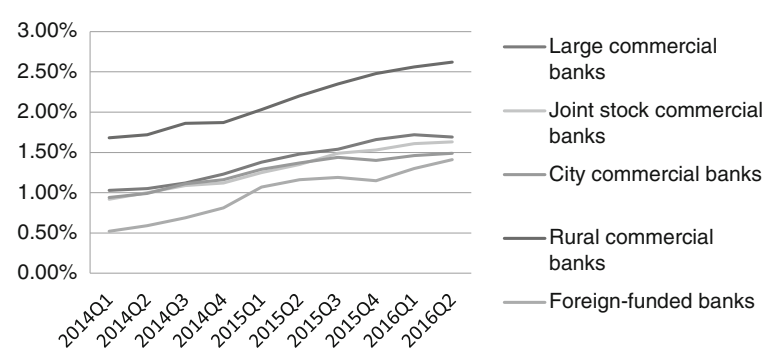

Fig. 2 Non-performing Assets of Commercial Banks. Source: China Banking Regulatory Commission

Furthermore, the Internet finance sector is still continuously creating new online-tooffline (OTO) scenarios to attract more customers and enhance user viscosity.

As the ecosphere of Internet finance continues to mature, it will penetrate deeper into the everyday scenarios of its consumers, in turn posing a significant threat to the dominant position occupied by banks.

\section{Endless financial innovations and diversification of investment and financing}

In recent years, there has been a boom in the financial markets, increased product varieties, and continuous financial innovations. The focus of capital markets range from derivatives to asset securitization, and then to P2P, crowdfunding, and others.

According to statistics by the Central Depository \& Clearing Co. Ltd., in 2015, the total asset securitization products issued nationwide were worth RMB 603.24 billion, equivalent to a growth of $84 \%$; their market stock was RMB 770.395 , equivalent to a growth of $129 \%{ }^{6}$ In 2016, the asset securitization market will progress toward the scale of trillion RMBs.

The crowdfunding industry has also achieved excellent results. According to incomplete statistics, as of the end of 2015, there were 283 normally operating crowdfunding platforms. For the entire 2015, the national crowdfunding industry successfully raised RMB 11.424 billion. This was the first year in history to exceed RMB 10 billion, registering an increase by $429.38 \%$ compared to $2014 .^{7}$ Additionally, the Securities Regulatory Commission has also announced that an equity crowdfunding pilot will be carried out this year.

Financial innovations can offer capital market participants, especially small and mediumsized enterprises (SMEs), more options, thus providing more convenient and personalized services. This creates significant competition with the traditional banking industry.

Table 1 The four high grounds of internet finance

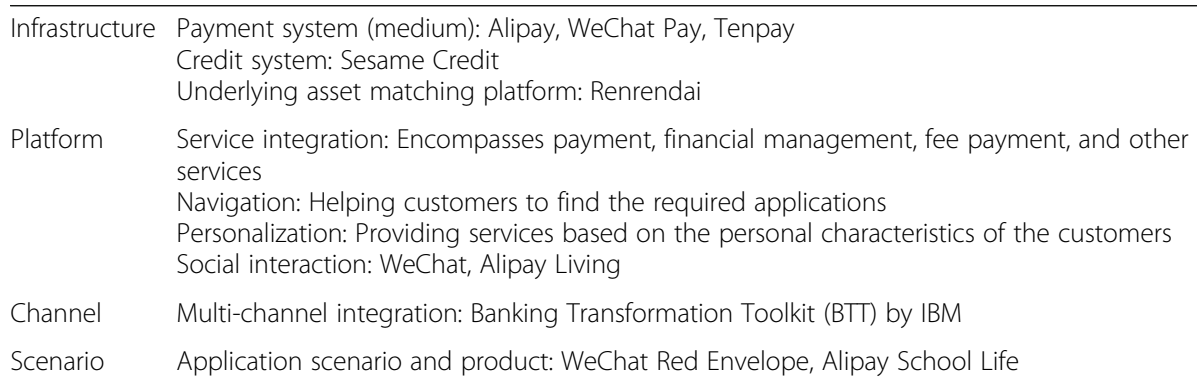




\section{Lack of information on banking customers leading to difficulties in creating credit}

The lack of information is the most prominent problem in the bank credit information system. On one hand, this has limited the business expansion of commercial banks, causing SMEs and individuals to have difficulties obtaining loans from banks. On the other hand, this has also led to the frequent occurrence of non-performing loans, and commercial banks have difficulties in screening and controlling loan quality.

Compared to Internet finance companies, the lack of information is the most obvious flaw in banks. Banks can obtain credit card bills, which only give a general overview of consumption scenarios. Conversely, Alipay is able to obtain the customers' consumption details, consumption ratios, and even their living expenses. This is because Alipay has created a Living function for its customers on its multi-functional integration platform. As credit is the cornerstone of financial activity, the banking industry has encountered a bottleneck in credit creation due limited customer information.

\section{Blockchain technology can revolutionize the underlying technology of banking businesses}

In view of these internal and external issues, the banking industry required new sources of growth in order to reverse the current downward trend. It is worth noting that the advancement of FinTech is an inevitable trend. If Internet finance, characterized by its revolution in application scenarios, is known as FinTech 1.0, then we are currently at FinTech 2.0, which emphasizes the revolution in the underlying technology. The greatest disruption of Internet finance for the traditional banking industry lies in enriching application scenarios and using big data analytics as foundation, in order to provide more personalized and convenient services to attract more customers. However, a large number of scenarios have already been developed, and innovations in scenario applications are becoming increasingly difficult. Therefore, new growth can only be achieved with genuine technological breakthroughs.

Blockchain technology is a type of underlying technology that can connect with a variety of scenarios. It can achieve asset digitization and point-to-point value transfer, thereby reconstructing the financial infrastructure. This sharply increases the process efficiency of the clearing and settlement of financial assets after transactions, while reducing costs. Hence, it resolves several existing problems in the banking industry to a large extent, which can be easily seen in Table 2 .

Needless to say, blockchain can become the core, underlying technology of the financial sector in the future. Presently, even BAT has already begun to implement blockchain. Hence, given its considerable lag behind the current FinTech 1.0, the banking industry should utilize the advantages of its resources and size, in order to actively conduct research and testing of blockchain applications. This will enable them to become the pioneers of technological applications that can lead and participate in the formation of new business landscapes, hence, continuously improving the capacity and content of high-value financial services and fostering new momentum for growth in the industry.

\section{Specific application scenarios for blockchain technology}

Blockchain can establish a credit mechanism in a situation where there is a lack of mutual trust among parties, thereby resolving the high costs caused by the non-technical aspects 
Table 2 Comparison of traditional banking businesses, Internet finance businesses, and blockchain + banking businesses

\begin{tabular}{|c|c|c|c|}
\hline & $\begin{array}{l}\text { Traditional banking } \\
\text { businesses }\end{array}$ & $\begin{array}{l}\text { Internet finance businesses } \\
\text { (FinTech 1.0) }\end{array}$ & $\begin{array}{l}\text { Blockchain + banks } \\
\text { (FinTech 2.0) }\end{array}$ \\
\hline \multirow[t]{3}{*}{ Customer experience } & Uniform scenarios & Rich scenarios & Rich scenarios \\
\hline & Homogenous service & Personalized service & Personalized service \\
\hline & Poor customer experience & $\begin{array}{l}\text { Good customer } \\
\text { experience }\end{array}$ & Good customer experience \\
\hline \multirow[t]{3}{*}{ Efficiency } & Many intermediate links & Many intermediate links & $\begin{array}{l}\text { Point-to-point transmission, } \\
\text { disintermediation }\end{array}$ \\
\hline & Complex clearing process & Complex clearing process & $\begin{array}{l}\text { Distributed ledger, } \\
\text { transaction = clearing }\end{array}$ \\
\hline & Low efficiency & Low efficiency & High efficiency \\
\hline \multirow[t]{3}{*}{ Cost } & $\begin{array}{l}\text { Large amount of manual } \\
\text { inspection }\end{array}$ & $\begin{array}{l}\text { Small amount of manual } \\
\text { inspection }\end{array}$ & Completely automated \\
\hline & Many intermediate links & Many intermediate links & Disintermediation \\
\hline & High costs & High costs & Low costs \\
\hline \multirow[t]{3}{*}{ Safety } & $\begin{array}{l}\text { Centralized data storage } \\
\text { Can be tampered }\end{array}$ & $\begin{array}{l}\text { Centralized data storage } \\
\text { Can be tampered }\end{array}$ & $\begin{array}{l}\text { Distributed data storage } \\
\text { Cannot be tampered }\end{array}$ \\
\hline & $\begin{array}{l}\text { Easy to leak users' } \\
\text { personal information }\end{array}$ & $\begin{array}{l}\text { Easy to leak users' personal } \\
\text { information }\end{array}$ & $\begin{array}{l}\text { Use of asymmetric encryption, } \\
\text { Users' personal information } \\
\text { is more secure }\end{array}$ \\
\hline & Poor safety & Poor safety & Good safety \\
\hline
\end{tabular}

of centralization. The processes of financial services are fraught with problems, such as efficiency bottlenecks, transaction lag, fraud, and operation risks. It is believed that the majority of these problems can be resolved as a result of applying blockchain technology.

\section{Payment clearing system: distributed clearing mechanism}

Interbank payments often rely on processing by intermediary clearing firms, which involves a series of complicated processes, including bookkeeping, transaction reconciliation, balance reconciliation, payment initiation, etc. Therefore, the process involved is lengthy and costly. Using cross-border payments as an example, as the clearing procedures for each country is different, a remittance requires nearly 3 days to arrive. This demonstrates the low efficiency and immense volume of occupied funds involved. ${ }^{8}$

Point-to-point payment can also be implemented using blockchain technology, thus eliminating the intermediary link of third-party financial institutions, which will greatly improve service efficiency and reduce the transaction costs of banks. This will also enable banks to satisfy the requirements for rapid and convenient payment clearing services for cross-border commercial activities. McKinsey has made an estimation which shows that the cost of each transaction in Cross-Border business can be greatly reduced due to the application of blockchain, the details are shown in Fig. 3.

Currently, a number of financial institutions started to test transactions on blockchain platforms. Standard Chartered uses Ripple, an enterprise-level blockchain platform, to implement its first cross-border transaction. For example, the platform took $10 \mathrm{~s}$ to complete a settlement process that currently takes the banking system and network 2 days to complete. ${ }^{9}$ The National Australia Bank (NAB) has also used Ripple's ledger technology 


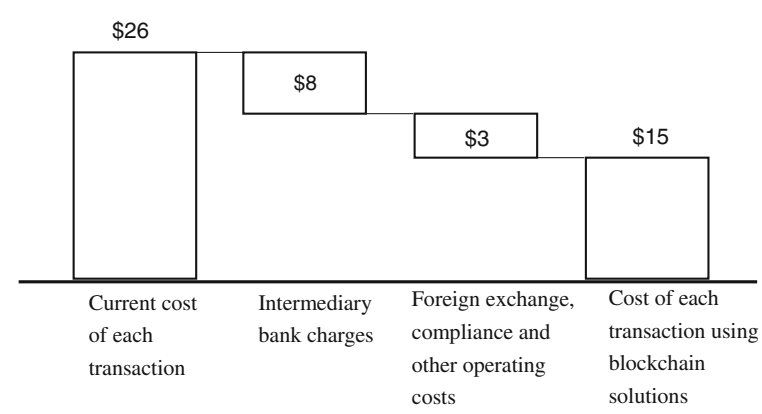

Fig. 3 Application of Blockchain in Cross-Border Payments. Source: McKinsey (Report by McKinsey: Blockchain-Disrupting the Rules of the Banking Industry,2016-05.)

to successfully transfer USD 10 from an NAB employee account to another employee's account in the Canadian Imperial Bank of Commerce. The process also took $10 \mathrm{s.}{ }^{10}$

\section{Bank credit information systems}

The ineffectiveness of bank credit information systems is mainly due to the following: first, the scarcity and poor quality of data makes it difficult to judge the situation of personal credit; second are difficulties in inter-institutional data sharing; third is the unclear ownership of user data, leading to difficulties in circulation due to concerns for privacy and security. Although the solutions to these problems will require the cooperation and participation of different stakeholders, blockchain technology can provide some assistance in addressing these issues.

\section{Establishing data ownership}

Every individual produces massive amounts of data on the Internet, which is extremely valuable as proof of their credit situation. Nevertheless, these data are currently being monopolized by large Internet companies. Hence, individuals are unable to establish their ownership or utilize these data. Additionally, in order to protect user privacy, data flow is difficult to achieve between these companies, which leads to the formation of data islands.

Blockchain technology can perform data encryption, which can help us control our own big data and establish ownership. This can further guarantee that the information is genuine and reliable, while also reducing the costs of data collection by credit agencies. Using blockchain technology, big data can become credit resources with clear personal ownership, and even establish the foundation of future credit systems.

\section{Promoting data sharing}

Blockchain can facilitate the automatic recording of big data by credit agencies, while also storing and sharing encrypted forms of the customer's credit status within institutions. This enables sharing credit data. The following blockchain credit solution has been proposed: during the "know your customer" (KYC) process, banks should store customer information in their own database, and then employ encryption technology to upload summary information for storage in the blockchain. When there are query requests, the original data provider can be notified using the blockchain and a query can be performed. Therefore, all parties can search external big data, while also not divulging their core business data (Blockchain 3.0 (12): Restructuring existing credit information system by blockchain credit $[\mathrm{EB} / \mathrm{OL}])$. 
Encryption technology can ensure that the summary and original information are consistent, thereby preventing the provision of false information that can mislead their counterparts. Within the framework of customer information protection regulations, the blockchain is able to realize the automated encryption and sharing or customer information and transaction records. This helps eliminate redundant work involved in KYC between banks.

\section{Distributed innovations in financial transactions}

Supply-chain finance involves an extensive amount of manual inspections and paperbased transactions. The process also has numerous intermediaries, a high risk of illegal transactions, high costs, and low efficiency. Blockchain technology can drastically reduce manual interventions and employ smart contracts in order to digitize procedures that rely heavily on paperwork. This would greatly improve the efficiency of supply-chain finance and reduce manual operational risks. With the supplier, buyer, and bank as the main trading parties, and the sharing of contractual information on a decentralized distributed ledger, smart contracts can ensure that payments are made automatically once a predetermined time and result is reached.

The application of blockchain technology in supply-chain finance can help reduce the costs to banks and trade financing enterprises. According to calculations by McKinsey, blockchain technology is expected to help banks reduce operational costs by USD 13.5-15 billion annually and cost of risk by USD 1.1-1.6 billion annually. Both trading parties will also be able to reduce their cost of capital by USD 1.1-1.3 billion annually, and operational costs by USD 1.6-2.1 billion annually. ${ }^{11}$ Furthermore, transaction efficiency improvement ensures a smoother flow of overall trade financing channels, which greatly increase the income of the overall trade chain.

Barclays Bank and an Israel-based startup have completed the first-ever blockchain-based trade transaction in the world. This transaction guaranteed the export of cheese and butter products worth around USD 100,000 from the Irish company Ornua to the Seychelles Trading Company. The transaction was performed on a platform set up by Wave, a partner company of Barclays Bank. Using blockchain technology, a transaction process that usually takes $7-10$ days was drastically reduced to $4 \mathrm{~h}^{12}$

Additionally, UBS has planned to establish a trade finance system using a distributed ledger, which can simplify global import and export transactions. In current large transactions, when the products are still in transit, the buyer's bank can use a letter of credit to eliminate the seller's credit risk. A letter of credit can weigh up to $500 \mathrm{~g}$ and include 36 documents that take 7 days to process, during which other risks may be generated. Conversely, blockchain technology can be used to program this procedure into a smart contract, thus reducing the processing time for letters of credit to $1 \mathrm{~h}$ and decreasing operational risk. ${ }^{13}$

\section{Obstacles to implementing blockchain technology in the banking industry Is disintermediation truly possible?}

True disintermediation requires complete decentralization as its foundation. Decentralization from a purely technical perspective does exist in some models. For example, for Bitcoin and other digital currencies, complete decentralization enables them to 
perform operations without the need for intermediaries. However, in the real world, many scenarios need to be safeguarded by a certain extent of centralization, especially when applied in the financial sector. Hence, we need to shift from a technical to a regulatory perspective. Achieving true decentralization is extremely challenging and could even be impossible; thus, true disintermediation cannot be achieved. Therefore, this point should be given due consideration when implementing blockchain technology. In order to meet the needs of reality, more centralized consortium and private blockchains can be derived from completely decentralized public blockchains. Table 3 shows the comparison of the different categories of blockchains.

Numerous banks and other financial institutions have come together to create the world's largest blockchain consortium, R3, which is a multi-centralized consortium blockchain. This is currently the most promising model in the banking industry.

Although blockchains have a technological advantage over banks as credit intermediaries, it is still too early for this technology to completely disrupt the existing financial system. Therefore, a "multi-center, weakly intermediated" scenario is likely to emerge (Chang and Han 2016). This is where banks use blockchain technology to improve their payment clearing systems and overcome certain obstacles in information communication, while also forming consortiums, thereby consolidating their position.

\section{Is there an efficiency problem?}

The efficiency problem of blockchains will need to be discussed in two parts. The efficiency of single transactions is influenced by technology and the degree of centralization. As transaction and clearing occur simultaneously, each transaction will need to be verified by all the nodes in the entire network, which is detrimental to its speed. This impact will become especially prominent when the nodes of the blockchain increase. On the other hand, the decreased in the efficiency of single transactions would improve transaction security. Moreover, the simultaneity of transactions and clearing would eliminate the problems of subsequent reconciliation. Overall, this brings undeniable improvements to the overall efficiency of banks.

Table 3 Categories of blockchains

\begin{tabular}{|c|c|c|c|}
\hline & Public blockchains & Consortium blockchains & Private blockchains \\
\hline $\begin{array}{l}\text { Degree of } \\
\text { centralization }\end{array}$ & Decentralized & Multi-centralized & Decentralized \\
\hline Participants & $\begin{array}{l}\text { Anyone can freely } \\
\text { participate and leave }\end{array}$ & $\begin{array}{l}\text { Specific group of people } \\
\text { who agree to enter an } \\
\text { alliance }\end{array}$ & $\begin{array}{l}\text { Central controller decides } \\
\text { members that can participate }\end{array}$ \\
\hline Credit mechanism & Proof of work & Collective endorsement & Self-endorsement \\
\hline Bookkeeper & All participants & Participants decide in negotiation & Self-determined \\
\hline Incentive mechanism & Needed & Optional & Not needed \\
\hline Prominent advantage & Self-established credit & Efficiency and cost optimization & Transparency and traceability \\
\hline $\begin{array}{l}\text { Typical application } \\
\text { scenario }\end{array}$ & Bitcoin & Clearing & Audits \\
\hline Load capacity & 3-20 times/second & 1000-10000 times/second & - \\
\hline
\end{tabular}

Source: Blockchain Laboratory, Research Institute of Chuancai Securities Co., Ltd. 
More importantly, the transaction speed of Bitcoin is deeply influenced by its decentralization. As for consortium blockchains, which are more suitable for the banking industry, the lower level of decentralization implies that the loss in speed is not too significant. Current tests have already shown that cross-border transactions only require less than $10 \mathrm{~s}$.

\section{How should blockchains be regulated?}

As blockchain technology is still in the development stage, the US Chair of the Federal Reserve remarked that regulatory rules will not be formulated yet in order to ensure sufficient freedom for innovation (US Federal Reserve Chair: Blockchains are potential shares, regulatory rules will not be formulated as yet [EB/OL]). However, the Chinese government has a cautious attitude towards this technology. The former director of the Bank of China, Li Li-Hui, stated that, "regulators should be involved in the formulation of technical and legal rules for financial blockchain technology, and now is the best time." ([Summit] Former Director of Bank of China Li Li-Hui - Opening Statement on the New Economic Horizons for Blockchain [EB/OL]).

The decentralization and self-governance of blockchains dilutes the concept of regulation, and has a critical impact on the existing system. However, any beneficial technology is accompanied by risks. Therefore, blockchain regulation is necessary, and should be formulated sooner rather than later.

\section{Regulatory sandbox}

The regulatory sandbox originates from the UK, which intends to give a more flexible space for innovations. The sandbox delineates a restricted scope with simplified market access standards and procedures. Given that consumers' rights are safeguarded, FinTech innovation enterprises or businesses are permitted to rapidly implement operations, and are allowed to expand within the testing conditions of the regulatory sandbox. Currently, the UK, Australia, and Singapore have announced the establishment of FinTech regulatory sandboxes (Hu Jin-Hua. Calls for regulating blockchains continues to increase, industrial bigwigs urges establishment of sandbox mechanisms [EB/OL]). Although China has proposed similar ideas for "flexible regulation," these have not been sufficiently standardized. Hence, their development should be accelerated in order to provide a controlled testing environment for the growth of blockchain technology.

\section{Industry standards}

As a core, underlying technology, more caution is required in the regulation of blockchain technology. Although the Bitcoin system has not been hacked in the 7 years since its establishment, the hacking attack on the DAO raised alarms. Several companies are now researching blockchain technology, and the security of this technology still needs to be tested using authoritative standards.

Recently, Standards Australia has submitted a request to the International Organization for Standardization to develop global standards for blockchain technology. The R3 blockchain consortium is also exploring the formulation of industry standards for interbank applications. In China, the blockchain technology research group of the Interbank Market Technology Standards Workgroup was established in August 2016. This workgroup is to 
conduct prospective research on interbank market blockchain technology, regulations, and legal framework.

\section{Information access mechanisms}

The immutable nature of blockchain systems is a guarantee of its authenticity. That is, once a piece of information enters the system, it cannot be modified. This eliminates the subsequent problems of fraud, but also implies that preliminary inspection of information needs to be more cautious. Therefore, stricter information access mechanisms need to be established, and the data on each node will need to be reviewed to ensure that fraud behaviors do not emerge. Once a transaction is initiated, it cannot be reversed. Hence, its authenticity and reliability needs to be verified in order to avoid accidental losses.

\section{Conclusions}

Blockchains could revolutionize the underlying technology of the payment clearing and credit information systems in banks, thus upgrading and transforming them. Blockchain applications also promote the formation of "multi-center, weakly intermediated" scenarios, which will enhance the efficiency of the banking industry.

It is worth noting that the problems of regulation, efficiency, and security have always sparked extensive debate in the process of each new financial innovation. However, history is not stopped by current obstacles, as the technical, regulatory, and other problems of blockchain technology will ultimately be resolved. Hence, the prospect of integrating blockchain technology into the banking industry will most likely occur in the near future.

\section{Endnotes}

${ }^{1}$ Report by McKinsey: Blockchain-Disrupting the Rules of the Banking Industry, 2016-05.

${ }^{2}$ Fortune: Blockchain Will Be Used by 15\% of Big Banks By 2017, http://fortune.com/ 2016/09/28/blockchain-banks-2017/, 2016-09-28/ 2016-10-23.

${ }^{3}$ Annual Report on China's Internet Finance Development (2016)

${ }^{4} \mathrm{BAT}$ is the abbreviation of the three major Internet companies in China: Baidu, Alibaba, and Tencent.

${ }^{5}$ International Financial News: "The Four High Grounds Seized by Internet Finance," http://paper.people.com.cn/gjjrb/html/2014-09/08/content_1474946.htm, 2014-09-08/ 2016-10-23.

${ }^{6}$ Central Depository \& Clearing Co., Ltd. 2015 Report on Developments in Asset Securitization

${ }^{7}$ Yingcan Consulting Co., Ltd. 2015 Annual Report of National Crowdfunding Industry

${ }^{8}$ Report by China International Capital Corporation, Changing the Infrastructure of the Financial Sector.

${ }^{9}$ Bitcoin ChainB: Standard Chartered Completed 10-Second Cross-Border Payment Using Blockchain, http://chainb.com/?P=Cont\&id=2327, 2016-09-30/ 2016-10-23.

${ }^{10}$ Shared Finance: Giant Leap by National Australia Bank: Successful Payment Transfer by NAB Using Blockchain, http://www.gongxiangcj.com/show-22-2130-1.html, 2016-09-22/ 2016-10-23.

${ }^{11}$ Report by McKinsey: Blockchain-Disrupting the Rules of the Banking Industry,2016-05.

${ }^{12}$ Weiyangx: Barclays Bank completes its first blockchain-based trade-finance transaction, http://www.weiyangx.com/205645.html, 2016-09-09/ 2016-10-23. 
${ }^{13}$ OKCoin.cn: After two years of experiments, UBS plans to establish blockchain-based trade-finance system, https://www.okcoin.cn/t-1016165.html, 2016-10-09/ 2016-10-23.

\section{Authors' contributions}

YG set up the logic frame, reviewed the now available researches, and make an analysis. CL collected the data and drew the figures and tables. Both authors read and approved the final manuscript.

\section{Competing interests}

The authors declare that they have no competing interests.

Received: 2 November 2016 Accepted: 16 November 2016

Published online: 09 December 2016

\section{References}

Blockchain 3.0 (12): Restructuring existing credit information system by blockchain credit [EB/OL]. http://www.8btc. com/blockchain-3-credit, 2016-05-18/2016-10-08.

Chang Jia, Han Feng (2016) Blockchain: From Digital Currencies to Credit Society [M]. CITIC Publishing Group.

Chinese Blockchain Technology and Application Development White Paper (2016) [EB/OL]. Informatization and Software Services Division, Ministry of Industry and Information Technology, 2016-10-18.

He Mei, Mao Jun-Hua. Changing the Infrastructure of the Financial Sector [J]. Report by The China International Capital Corporation, 2016-01-29.

Hu Jin-Hua. Calls for regulating blockchains continues to increase, industrial bigwigs urges establishment of sandbox mechanisms [EB/OL]. http://www.chinatimes.cc/article/60321.html, 2016-09-03/2016-10-08.

Joseph Luc Ngai et al. Blockchain—Disrupting the Rules of the Banking Industry [J]. Report by McKinsey, 2016-05.

Mu Qi-Guo. First Report on Survey of Blockchain Technology: Potential to Disrupt All Industries [J]. Report by Chuancai Securities Co., Ltd, 2016-01-12.

Mu Qi-Guo. Second Report on Survey of Blockchain Technology: Evolution of Blockchain Technology [J]. Report by Chuancai Securities Co., Ltd, 2016-01-25.

[Summit] Former Director of Bank of China Li Li-Hui - Opening Statement on the New Economic Horizons for Blockchain [EB/OL]. http://chainb.com/?P=Cont\&id=2263, 2016-09-24/2016-10-08.

The First Digital Currency Report of the International Monetary Fund [EB/OL]. http://mt.sohu.com/20160127/ n436054806.shtml, 2016-01-27/2016-10-08.

US Federal Reserve Chair: Blockchains are potential shares, regulatory rules will not be formulated as yet [EB/OL]. http:// www.gongxiangcj.com/show-22-2174-1.html, 2016-09-29/2016-10-08.

Wang Wei. Review and Outlook of China's Banking Industry for the First Half of 2016 [j]. Report by Pricewaterhouse Coopers, 2016-09.

\section{Submit your manuscript to a SpringerOpen ${ }^{\circ}$ journal and benefit from:}

- Convenient online submission

- Rigorous peer review

- Immediate publication on acceptance

- Open access: articles freely available online

- High visibility within the field

- Retaining the copyright to your article 